\title{
Teaching about Leadership or Teaching through Leadership?
}

\author{
Jan Seger, Ph.D. \\ GIH - the Swedish School of Sport and Health Sciences \\ Box 5626, SE-114 86 \\ Stockholm, SWEDEN \\ Urban Bergsten, Ph.D. \\ GIH - the Swedish School of Sport and Health Sciences \\ Box 5626, SE-114 86 \\ Stockholm, SWEDEN
}

\begin{abstract}
This article is based on experiences and convictions from teaching leadership to students on the university and college levels. Teaching through leadership rather than about leadership is advocated. Student learning and facilitator teaching are contrasted. Leadership is viewed more as a mutual relationship rather than certain personality traits of the leader. The importance of understanding group processes is stressed.
\end{abstract}

\section{Background}

During the last 20 years we have been teaching leadership at a University College for undergraduate students, becoming physical education teachers as well as professional coaches, health promotion professionals and sport managers.

Firstly, it is not only semantics when we argue that the challenge for the teacher is not to teach leadership, but rather to create possibilities for learning, capturing, and building leadership, a process resembling Kolb's (1984) learning cycle. His work entitled, Experiential learning: Experience as the source of learning and development, as well as other researchers work has examined this concept (i.e., $\mathrm{Ng}$ et al., 2009). Working experientially and critically means challenging students' ways of thinking about leadership (Sinclair, 2007).

Furthermore, conventional teaching has been criticized at times. For example, Beard and Wilson 2006) have suggested:

Traditional learning, with the teacher or trainer spouting facts and figures and with pupils or participants regurgitating the 
information without deeper involvement is a very ineffective form of learning. A much more effective and long-lasting form of learning is to involve the learner by creating a meaningful learning experience (p. 1).

One important prerequisite is that students are viewed as initially being reasonably knowledgeable concerning leadership in the common sense and that, to a certain extent, they recognize leadership behavior and actions. In other words, all students have experienced leadership and group processes during earlier school years, training sessions, jobs, and other life situations, but without having had the opportunity to analyze and reflect.

Leadership development is offered to students during the second half of their teacher education. Studies in leadership demand a certain level of maturity in order to gain the personal growth that is one desirable outcome from leadership training.

We work in The Leadership Center which is located in a separate section of the college campus. This relative seclusion can support and strengthen the experiences from the leadership classes. The Center can be viewed more as a laboratory than just general seminar rooms. Our courses usually cover five or ten weeks of studies wherein the students in groups of 20-30 can concentrate entirely on the study of leadership and group processes. Usually two teachers work together in the room, making interactions with the students more intense and also making the assessments and evaluations from the courses more reliable and valid. Co-leadership or shared leadership offers a number of advantages (Heenan \& Bennis, 1999; O’Toole, Galbraith \& Lawler, 2002). During leadership classes, students generally meet twice a week, always in the same room, working full days, and in the in-between-time they are expected to read, reflect, and document.

\section{To Teach Through or About?}

Usually leadership education is directed towards teaching about leadership in a cognitive manner. Typical programs promote leadership literacy, but not leadership competence (Allio, 2005). Our conviction is that leadership skills are best learned by teaching through leadership, not about leadership, meaning that it is important to create opportunities for students to learn, choose, and form their leadership. Briefly students are introduced to different practice situations, a form of experiential learning, wherein leadership and group processes are illustrated and experienced. The processes here and now create a foundation for a theoretical elaboration. Our aim is to involve the cognition, the emotion, and the drive of leadership. Teachers act as role models. This also means that exclusively 
theoretical lectures on leadership skills are avoided, and instead short introductions on different theories and subjects after a learning session are offered. Students are then encouraged to read more about the specific topics (Beard \& Wilson, 2006).

Teachers, or rather facilitators, at the Center are working both as management consultants in private and public organizations, and meeting students on campus. Every now and then students take part in authentic projects in companies and public agencies, thus getting opportunities to bring theory closer to practice. Hence, the concept of education through leadership infers that students are offered learning situations in order to capture, develop, and deepen their own leadership skills.

\section{Leadership as a Relation}

In the following paragraphs some examples are presented concerning the way we work during the leadership studies and also some additional ideas about leadership and teaching.

The main focus of leadership research since the 1930s has been upon the leader as a person. There is an abundance of research where successful leadership is described as a set of personality traits (Bono \& Judge, 2004; Yukl, 2009). Skills and certain characteristics and personality traits were relevant predictors for successful leader behavior.

A conceivable consequence of this research orientation is that certain individuals were born to be leaders rather than having developed skills through practice, training, and learning. However, hundreds of studies about successful leadership have been carried out without showing any clear correlation between personality traits and efficient leadership performance (Bryman, 1992; Grint, 1997;

Hagström, 2003; Yukl, 2009).

Our need for leaders has been investigated and described by many researchers (Bion, 1961; Tubbs \& Carter, 1978; Moxnes, 1998). It seems like we, as group members, constantly want someone to glorify or to blame. This focus on the leader reflects dependence and an escape from responsibility as a group member.

We prefer to regard leadership as a relationship, where the ability to comprehend the needs of the co-workers and to show empathy, will create a perspective and motivation for the personal development for the leader. As an example, our ambition is to live the concept of leadership as a relationship by using feedback extensively. Feedback has been proposed as a powerful factor in adult learning 
(Halpern, 2004; DeRue \& Wellman, 2009). The students are encouraged to reflect on their own behavior as well as give feedback to each other and to the teachers. Individual feedback is given frequently, first and foremost in connection to seminars and lectures managed by the students. In order to illustrate the concept of handling conflicts and to give students an opportunity to practice, role plays with subsequent discussions are offered.

\section{Managing Boundaries}

One of the areas we strongly focus upon, besides the ability to give and receive feed-back, is the importance and the awareness of handling boundaries. Boundaries are often considered to be negative and repressive. They can be associated with being authoritarian and unfriendly. The consequence can be that the leader avoids setting boundaries. Instead, statements from the leader like "my door is always open," "we are one big, happy family," and "I am part of the group, with very little power" can characterize the working place.

To us this means that the leader abdicates, making his mandate indistinct and unclear. Therefore, handling boundaries is an important leadership skill, being clear and visible; in fact being professional.

Some leaders want to bring about a popular image by trying to be one in the group, fulfilling personal needs of confirmation and social contact. We maintain the view that every leader should understand the importance of upholding this boundary. Without integrity it will be hard for the leader to give valuable and credible feedback and to stay detached. Upholding the boundary will gain respect, motivation, and liberate energy.

\section{"The Reflecting Team"}

The pedagogical setting of the reflecting team is used to increase the participation of the students and to encourage them to express their views as well as feelings and interact with each other (Andersen, 1991). The concept means that one group of 4-6 students sit in a circle discussing a matter of importance, and the rest of the students listen, sitting in an outer circle. Only the students in the middle have the mandate to participate in the conversation. The other students are encouraged to listen actively and to reflect, and after a set time a new group of students is invited to pick up on the discussion. For every new group the discussion becomes deeper and more focused. The teachers do not lead the conversation and no summary at the end is necessary because everyone has listened and participated during the discussion. This approach enhances the learning process and encourages a continued reflection. There are some educational qualities working in reflecting 
teams. Time is the boundary, not the achievement. You practice your skills by both listening to your inner conversation and to the outer conversation everyone can hear. The members in the team feel more equal, since there is no chairperson. The conversation in the inner circle is usually more serious and open with a silent outer circle listening, and, moreover, everybody has heard all discussions in the room.

\section{Retrospect}

One aspect of reflections is that every morning in class, the period starts with a review from previous seminars. The students try to remember and answer questions such as "What did we do?" "How did the learning exercise and discussion affect me?" "My thoughts and feelings are?" "Have I met the phenomena before?" "How can I apply this new knowledge and experience for further development?" The subsequent discussions help students to confirm their experiences, to internalize their learning, to open up for colleagues' reactions and to prepare for future leadership behavior. This procedure emphasizes process learning in contrast to pure cognitive learning.

\section{The Mutual Dependence of the Leader and the Group}

The prevailing view among students at our university college is that leaders take the lead, they are visible, they are heard and they push and control. In addition, conscious leadership implies that the group behaves in a predicted, desirable way, in a kind of stimuli-response reaction. As a consequence of this mental image, many participants attending leadership seminars, express an expectation to get "ready-made tools and instruments", to handle situations in a predetermined way.

During classes at the Center we present an alternative view regarding the interaction between leaders and the group. With a metaphor, professional leadership sometimes means to walk first in the line, at other occasions to walk beside, and in a mature group maybe you, as a leader, should walk behind the group. The group is constantly occupied in influencing the leader to behave and act in ways that the group desires. Within the dynamic oriented research concerning group behavior, leadership is defined as a dynamic process where the leader and the group interact in such a way that it is not necessarily the leader who leads and the followers who follow (Granström, 1986). The impact from the group upon the leader is generally not conscious. These processes are not easy for the untrained to see, perceive, and understand (Bion, 1961; Moxnes, 1998). In role plays and observations students are made aware of these interactional processes. 


\section{Methodological Perspectives on Developing Leadership}

As a principle for our teaching, the managers and the students are invited to educational methods focusing on understanding processes and opportunities for reflection. Since students do not attend any other classes while participating in leadership classes, it is easier for them to focus and concentrate.

Knowledge and skills not only deal with experiencing learning exercises, roleplays and mini-lectures, but also the ability to assimilate, to reflect, to analyze, to evaluate, and to synthesize. In this article the reflecting team has been described, where concepts are created and understood by a form of dialogues, and dialogues about dialogues, integrated with reflective listening (Andersen, 1991).

The learning processes by listening to experiences, reflections and view points from other colleagues are emphasized. Students are taught to focus not only upon the vertical learning processes (i.e., those between the student and the teacher). Learning is also taking place when interacting with a fellow colleague horizontal learning.

One example of horizontal learning is peer-feedback. Reflexive journal assessment is also used extensively.

As a complement to regular leadership literature the students and the managers are required to read fiction written by authors on an acknowledged level. Fiction literature, quality films, and theater plays are ways to learn how to listen and to practice consciousness and sensitivity for interpersonal processes. In contrast to traditional, quantitative, external assessment, our evaluations usually take place continually during classes and focus on inner learning processes within the student. Aulls (2004) found that student perceptions of good and poor university education emphasized emotions more frequently than academic learning outcomes.

Students participate in leadership classes during their last years of their studies, since you need maturity to internalize your learning, allow personal growth and apply a relativistic way of thinking (Perry, 1999). Our way of thinking includes the fact, that training in leadership skills and behavior should strive for a change and development of the students' understanding of themselves, and their surrounding world.

Argyris and Schön (1978) have postulated that learning in organizations can be of first order and of second order learning. The former, also called the single loop learning, implies that you directly from casual relationships take necessary steps, 
to do more or less of that specific behavior. Second order learning or double loop learning refers more to an understanding of the problem, the connections and the consequences. Here the focus is on reflecting, acting to understand and changing the conditions, rather than establishing new rules and regulations.

A challenge for us, as academics, is to handle the interaction between theory and practice. Often in leadership training, the everyday solutions, the tools, have a tendency to dominate. The theoretical anchoring is necessary in order to the reach another level, to understand the situation, not just to fix it (i.e., striving for double loop learning). Another aspect of academic studies is critical thinking (Burbach et al., 2004). If you have the competence to see connections and consequences, you have the ability to link your learning and conclusions to societal aspects and processes. At this level you probably have the capability to be critical towards certain tendencies and trends within the field of leadership training and their consequences for working life in society.

\section{Conclusion}

Our leadership classes have been evaluated in retrospect through questionnaires, with former students having worked for some years in different positions as leaders and teachers. Leadership training was mentioned as the subject area affecting students the most. The answers also indicated that leadership education had influenced them personally as well as professionally.

For us, experiential learning is one important key element in our way of regarding and developing leadership. Beard and Wilson (2006) offer a definition:

"Experiential learning is the sense-making process of active engagement between the inner world of the person and the outer world of the environment" (p. 2).

Furthermore, after taking part in our leadership classes, each participant has developed an individual leadership style, based on needs, background and preferences. Finally, we believe that the best way to learn leadership is when leadership and connected processes appear in the room. 


\section{References}

Allio, R. J. (2005). Leadership development: teaching versus learning. In Management Decision, 43(7/8), 1071 - 1077.

Andersen, T. (1991). The reflecting team: Dialogues and dialogues about the dialogues. W. W. Norton \& Company.

Argyris, C., \& Schön, D. (1978). Organizational learning. Reading. AddisonWeasley.

Aulls, M. W. (2004). Students' experiences with good and poor university courses. Educational Research and Evaluation, 10(4-6), 303-335.

Beard, C., \& Wilson, J. P. (2006). Experiential learning. A best practice handbook for educators and trainers ( $2^{\text {nd }}$ ed.). London, Kogan Page.

Bion, W. R. (1961). Experiences in groups: And other papers. Tavistock. Reprinted, 1989 Routledge.

Bono, J. E., \& Judge, T. A. (2004). Personality and transformational and transactional leadership: A meta-analysis. Journal of Applied Psychology, 2004, 89(5), 901-910.

Bryman, A. (1992). Charisma and leadership in organizations. London: SAGE.

Burbach, M. E., Matkin, G. S., \& Fritz, S. M. (2004). Teaching critical thinking in an introductory leadership course utilizing active learning strategies: A confirmatory study. College Student Journal, 38(3), 482- 494.

DeRue, D. S., \& Wellman, N. (2009). Developing leaders via experience: The role of developmental challenge, learning orientation, and feedback availability. Journal of Applied Psychology, 94(4), 859-875.

Granström, K. (1986). Dynamics in meetings. On leadership and followership in ordinary meetings in different organisations. Linköping: Linköping studies in Arts and Science.

Grint, K. (Ed) (1997). Leadership: Classical, contemporary and critical approaches. Oxford University Press. Oxford. 
Hagström, T. (2003). Adult development in post-industrial society and working life. The Institute of Education. University of Stockholm.

Halpern, D. F. (2004). The development of adult cognition: Understanding constancy and change in adult learning. In D. A. Day, S. J. Zaccaro, \& S. M. Halpin (Eds.), Leader development for transforming organizations (pp. 125-152). Mahwah, NJ: Erlbaum.

Heenan, D. A., \& Bennis, W. (1999). Co-leaders. The power of great partnerships. New York: John Wiley \& Sons.

Kolb, D. A. (1984). Experiential learning: experience as the source of learning and development. New Jersey: Prentice-Hall.

Moxnes, P. (1998). Fantasies and fairy tales in groups and organizations: Bion's basic assumptions and the deep roles. European Journal of Work and Organizational Psychology, 7(3), 283-298.

Ng, K. Y., van Dyne, L., \& Ang, S. (2009). From experience to experiential learning: Cultural intelligence as a learning capability for global leader development. Academy of Management Learning \& Education, 8(4), 511526.

O'Toole J., Galbraith J., \& Lawler E. E. I. (2002). When two (or more) heads are better than one: The promise and pitfalls of shared leadership. California Management Review, Summer 2002, 44 (4), 65-83.

Perry, W. (1999). Forms of intellectual and ethical development in the college years: a scheme. San Francisco, Calif. Jossey-Bass Publishers.

Sinclair, A. (2007). Teaching leadership critically to MBAs : Experiences from heaven and hell. Management Learning, 38(4), 458-472. Sage Publications, Los Angeles, London, New Delhi and Singapore.

Tubbs, S. L., \& Carter, R. M. (1978). Shared experiences in human communication. Transaction Publishers.

Yukl, G. A. (2009). Leadership in organizations. ( $7^{\text {th }}$ ed.). Prentice Hall. 


\section{Author Biographies}

Jan Seger, Ph.D. in medicine, secondary school teacher, physical education teacher, has taught different subjects, among them leadership, at university level for about 25 years. Research in biomechanics, physiology and leadership.

Urban Bergsten, Ph.D., in pedagogy, secondary school teacher, management consultant, and teacher in leadership. Research in adult education and leadership. 